\title{
Mitigating shear lag in tall buildings
}

\author{
Himanshu Gaur ${ }^{1}\left[\right.$ : Ravindra K. Goliya ${ }^{2}$
}

Received: 15 September 2014/ Accepted: 6 July 2015/Published online: 27 August 2015

(c) The Author(s) 2015. This article is published with open access at Springerlink.com

\begin{abstract}
As the height of building increases, effect of shear lag also becomes considerable in the design of highrise buildings. In this paper, shear lag effect in tall buildings of heights, i.e., 120, 96, 72, 48 and 36 stories of which aspect ratio ranges from 3 to 10 is studied. Tube-in-tube structural system with façade bracing is used for designing the building of height 120 story. It is found that bracing system considerably reduces the shear lag effect and hence increases the building stiffness to withstand lateral loads. Different geometric patterns of bracing system are considered. The best effective geometric configuration of bracing system is concluded in this study. Lateral force, as wind load is applied on the buildings as it is the most dominating lateral force for such heights. Wind load is set as per Indian standard code of practice IS 875 Part-3. For analysis purpose SAP 2000 software program is used.
\end{abstract}

Keywords Tall buildings - Shear lag effect - Earthquake load $\cdot$ Wind load

\section{Introduction}

In 1969, Fazlur Khan first classified the structural system for designing of tall buildings. At that time rigid frame was the most dominating structural system that prevailed in that era for the design of tall buildings. Falzlur Khan first

Himanshu Gaur

himanshugaur82@gmail.com

Ravindra K. Goliya

ravindra.goliya@juet.ac.in

1 Dire Dawa University, Dire Dawa, Ethiopia

2 Jaypee University of Engineering \& Technology, Guna, India introduced a new structural system named tubular structural system and designed the Sears Tower, 108 story high world tallest building with it at that time.

Again in 2007, by Ali and Moon this structural system was re-classified (Ali and Moon 2007). These structural systems are classified depending upon the height of the building selected for designing. Other parameters like loading conditions, architectural requirement, site conditions and functional requirement are also imperative. For high-rise buildings he classified them as framed tube structure, diagrid building structural system, outrigger structure, bundled tube, tube in tube and frame with shear wall, etc.

This paper presents a detailed discussion about the shear lag effect, a major phenomena that controls the designing of tall building of tube structural system. Tube in tube with façade bracing system is used for designing the buildings of 120 stories high. Objective of this study is to study the shear lag effect and its correlation with stiffness-based design in tube structural system.

In tube structural system, buildings are designed considering a hollow concrete box projecting out of ground designed as a cantilever beam in which façade columns are spaced closer and connecting beams are considerably deep making it hollow box-like structure which supports the lateral loads (http://en.wikipedia.org/wiki/Tube_(struc ture); Ali and Moon 2007; Siavash 2001). This idea also comes from the nature of Bamboo tree which is very tall and thin. At each node, Bamboo is stiff enough resembling the stiffened diaphragm of a building (Mark 2011).

In this paper, one tube is provided at the outer periphery of the total plan area and another tube is provided inside the plan area in which core area used is $25 \%$ of the total plan area. It is found that with this tube-in-tube structural system, top lateral deflection limit could be controlled with $\mathrm{H} / 500$ as an engineering decision (Mendis et al. 2007). 


\section{Shear lag effect and stiffness of a building}

Loads on tall buildings can be divided into two vertical or gravity loads and lateral loads. Tubular structure is the most efficient structural system that utilizes both kinds of loads for designing a tall building. Providing column-free area between the core and the perimeter columns maximizes gravity loads coming on outer columns which increase building's stability in overturning.

With the application of lateral load, column deflects in lateral direction and beam deflects in bending. This gives rotation of beam column joint. Because of the rotation of beam column joints, shear lag effect is induced in a building. Shear lag effect can be observed in any hollow box-like structural system which is loaded laterally. An example can be a hollow box girder that is used in the designing of bridges.

Motivation of this study stems out from the thinking that perhaps shear lag effect influences the design of tall buildings with tubular structural system. Controlling the shear lag can perhaps control the lateral deflection of the building. Theoretically, if the limit is reached of beam column joint rotation to be zero, panel starts behaving like a shear wall.

In this paper, shear lag effect is being studied and is correlated with stiffness of the building. Studies are also done for the different patterns of bracing systems. For convenience and to do relative study for shear lag effect, cross-sectional dimensions of beam and columns, their alignments (column) and the material properties are not changed with height of the building.

\section{Literature review}

Fazlur Khan in 1961 first had the idea of tube structural system. He first designed a 43-story DeWitt-Chestnut Apartment Building in Chicago. After that he designed world's tallest building Sears Tower with nine-bundled tube in Chicago (http://en.wikipedia.org/wiki/Tube_(structure)). As the building becomes tall, say more than 60 stories, tubular structure itself becomes inefficient for withstanding lateral loads because of shear lag. It much more starts behaving like rigid frame structure. In which in web panels, bending deflection in beam and columns becomes high, consequently increasing the shear lag. To control these deflections and hence to increase the building's stiffness, he suggested three different methods. One of which is by providing additional tube inside the building plan called tube-in-tube structural system. Second one is by providing bundled tube (Ali and Moon 2007). Third way of increasing the lateral stiffness of the structure is by providing bracing system which efficiently reduces the shear lag and increases the building performance to support the lateral loads.

In 2007, Johan Leonard presented his studies on shear lag effect in diagrid building structural system (Leonard 2007). He studied the shear lag effect in 60 stories high buildings by varying diagrid angles. He found that shear lag effect keeps on increasing as the angle of diagrid changes from $31^{\circ}$ to $90^{\circ}$. In his studies top lateral deflection was found minimum for the diagrid angle of $63.4^{\circ}-71.6^{\circ}$.

In 2007, K.S. Moon studied methods of designing diagrid building structural system (Moon 2008, 2009, 2012; Moon et al. 2007; Thomas and Viktor 2010). Theoretically he proved that for maximum shear rigidity of diagrid, optimal angle should be falling near $35^{\circ}$, but for maximum bending rigidity it should be at $90^{\circ}$ from horizontal. So, optimal angle should fall between these two values, i.e., $35^{\circ}$ and $90^{\circ}$. In the analysis he discovered that optimum diagrid angle for building of height from 60 to 20 stories falls between $53^{\circ}$ and $76^{\circ}$. He also concluded that this optimal angle of diagrid decreases as the height of the building decreases.

K.S. Moon again carried out his studies on braced tube structural system of 100 story high building with various diagonal configurations. In his studies he found that diagonal angle of bracing between $35^{\circ}$ and $55^{\circ}$ is the best possible structural configuration for material-saving design (Moon 2012).

\section{Shear lag effect}

Shear lag effect in a building can be best understood with the help of Fig. 1. In this figure cross section of a building is shown in which a moment is induced because of the application of lateral load. Figure shows the theoretical and real distribution of axial stresses in peripheral columns. Now considering the whole structure as a cantilever beam, axial stress generated in the columns of outer periphery are the bending stresses. This statement follows with the theory of bending.

Again with the theory of bending, variation of these stresses along any panel (flange or web) must be varying linearly. Real distribution of these axial stresses in panels can be observed in the figure which is not linear. In the flange panel, magnitude of axial stress at the corner side is high in comparison to the columns of middle panel. So in the flange panel middle columns axial stress lags behind with that of the corner columns. Same kind of nonlinear distribution of axial stress can also be observed in the web panels. This kind of nonlinear distribution of axial stress along the flange and the web panels is called as shear lag effect. 
Fig. 1 Axial stress distribution in the columns of the building in web as well as in flange panels

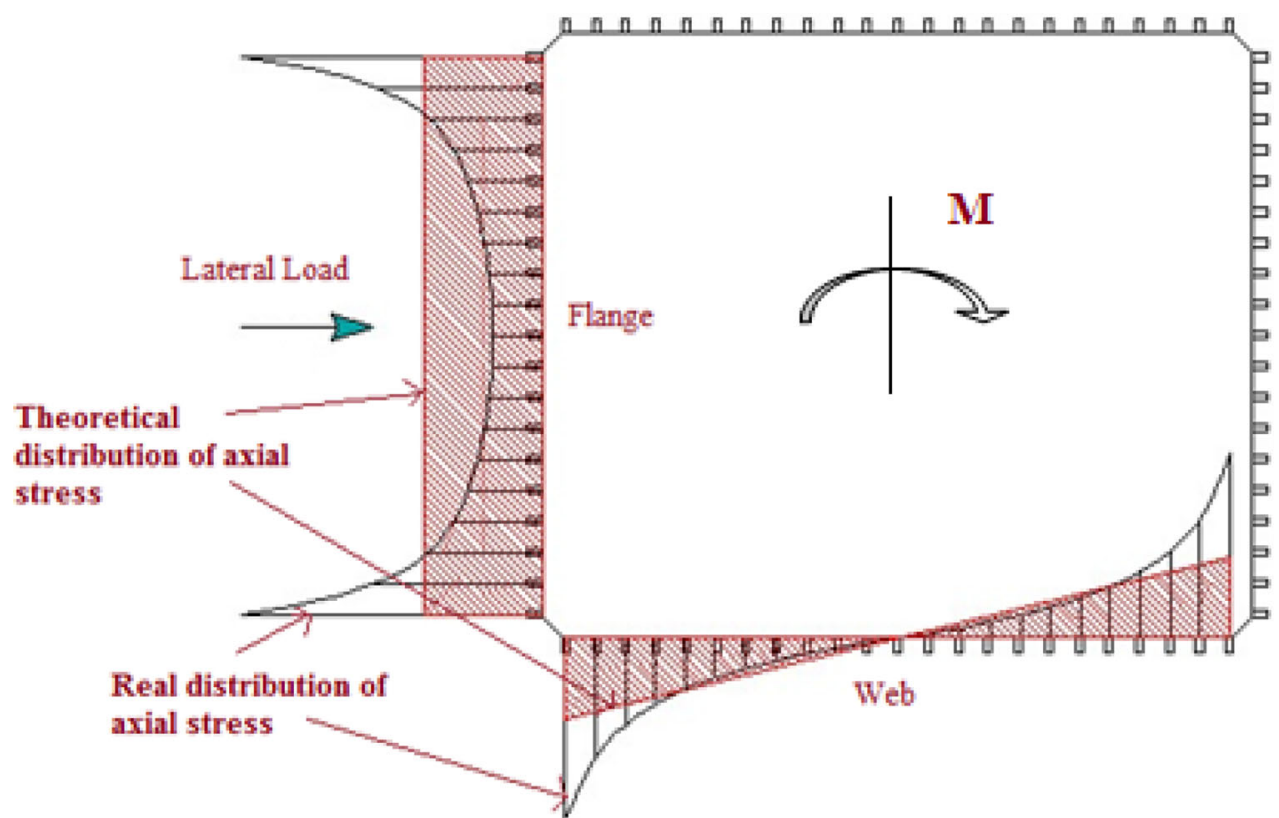

To illustrate more a three-dimensional model of a cantilever beam of hollow square cross section resembling a tube is modeled with thin shell element in SAP 2000 (Fig. 2). The beam is $3 \mathrm{~m}$ long and cross-sectional dimensions are $0.5 \mathrm{~m} \times 0.5 \mathrm{~m}$. This beam is loaded with uniformly distributed load acting approximately till mid of its length as shown in figure.

Type of loading resembles with the kind of wind load that is typically considered to act at each node laterally. Results are displayed for the loading till mid-length of the beam for better demonstrating the concept of positive and negative shear lag (Leonard 2007).

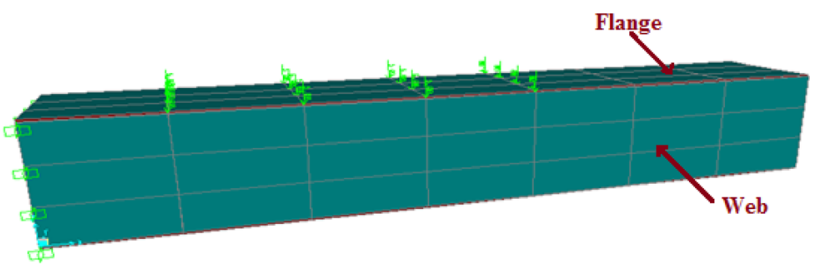

Fig. 2 Three-dimensional view of the finite element model of the cantilever beam $3 \mathrm{~m}$ long loaded with UDL till $1.71 \mathrm{~m}$ length from the fixed end

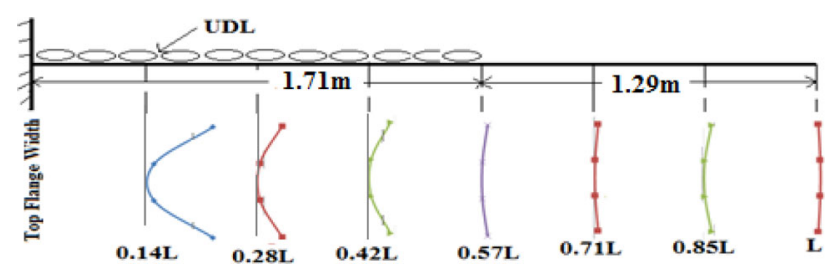

Fig. 3 Top flange deformation in the longitudinal direction
After running the analysis, the beam displayed the deformed shape. As stress is directly proportional to strain, so studying the deformed shape demonstrate the stress distribution in the beam.

In Fig. 3, its top flange deformation along the width is shown. These deformations are shown at regular intervals along the length of the beam. These deformations are magnified for better understanding. It can be observed that till length $0.85 \mathrm{~L}$, deformation in the corner part is more than the deformation in the mid-part of the flange. For the further length mid-portion of the flange is showing more deformation in comparison to the corner part.

\section{Positive and negative shear lag, shear lag ratio}

Near the fixed end of the cantilever beam, along the flange width, stresses are high in corner side in comparison to middle of the panel. This type of shear leg effect is called positive shear leg. Towards the free end, in the middle part of the flange, stresses are high in comparison to corner part of the flange. This type of shear lag is called negative shear lag.

Shear lag ratio is introduced to measure the magnitude of shear lag effect. It is the ratio of stress of maximum stress at the corner side of the flange panel to the middle of the panel where stress is least. This ratio tells the effect of shear lag in the panel. Less than one value of shear lag ratio describes the negative shear lag. Table 1 shows variation of shear lag ratio along length for this beam. 
Table 1 Shear lag ratio in beam

\begin{tabular}{ll}
\hline Beam location from fixed support $(\mathrm{m})$ & Shear lag ratio \\
\hline 0.428571 & 1.252353205 \\
0.857142 & 1.054040404 \\
1.285713 & 1.039034627 \\
1.714284 & 1.010363707 \\
2.142855 & 1.000957671 \\
2.571426 & 1.002097235 \\
3 & 0.999809705 \\
\hline
\end{tabular}

\section{Building modeling}

For all buildings, plan area is $42 \mathrm{~m} \times 42 \mathrm{~m}$. At the outer periphery, columns are spaced at $3.5 \mathrm{~m}$ center to center and floor height is set as $3.5 \mathrm{~m}$ each. For controlling lateral deflection, a central core is also provided. Building's façade beam-column connections are moment connections. Central core area is $25 \%$ of the total plan area. Area between central core and building façade is column free which spans $10.5 \mathrm{~m}$. Inner core column connects with outer peripheral columns with rigid diaphragm. Rigid diaphragm means that in-plane deformations are negligible, whereas out-of-plane deformations (in bending) are allowed. Now, in this tube-in-tube structure where diaphragm is rigid, entire lateral load is carried by the peripheral and inner core columns only. Wind load is applied according to IS

Table 2 Dimensions of the members for 120 story high building

\begin{tabular}{lc}
\hline Name of the panel & Size $\left(\mathrm{m}^{2}\right)$ \\
\hline Beam & $0.5 \times 1.25$ \\
Column & $1 \times 3$ \\
Corner columns & $1.5 \times 1.5$ \\
\hline
\end{tabular}

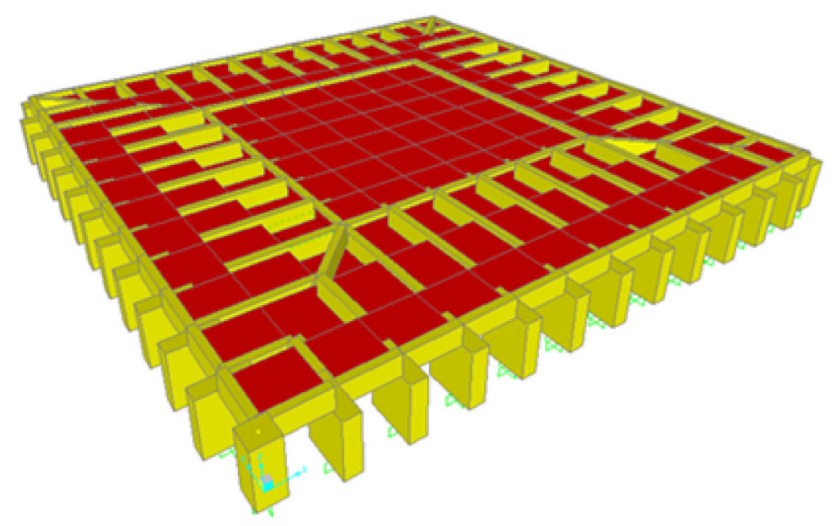

Fig. 4 Perspective view of the ground story

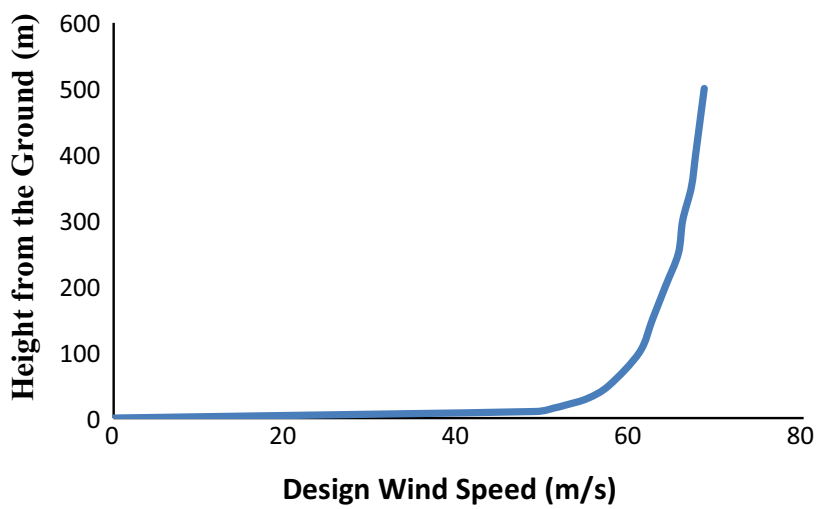

Fig. 5 Design wind speed according to IS 875 for calculation of lateral load on building models

875, Part-3 (BIS 1987). Depending upon several factors like place, category of the terrain and class of structure selected, design wind speed for lateral load calculation is shown in Fig. 5. Building bracing systems are connected with pined connections. Cross-sectional dimensions of members of 120 story high building are shown in Table 2 (Fig. 4).

\section{Shear lag effect in a building}

Objective of this paper is to study the shear lag for different heights of buildings and also to investigate it for different possible geometric patterns of bracing systems.

Figure 5 shows the shear lag effect in a 120 stories high framed tube-in-tube structural building. It can be seen in this building that at the bottom of the building there is positive shear lag effect. With increasing height, it continues to decrease till it becomes zero. For further height it converts to negative shear lag (Fig. 6).

In these results it is found that for 120 stories high building, value of shear lag ratio starts changing from positive to negative at around 30th story. For 96 stories high building, this change comes around at 25th story. For 72 stories high building, it is at 20th story and for 48 and 36 story high building it is around at 15 th story.

\section{Problem statement}

Fulfilling the geometric requirement of the building, bracing systems are provided with an inclination of $45^{\circ}$, $63.43^{\circ}, 71.56^{\circ}, 75.96^{\circ}, 80.53^{\circ}$ and $84.28^{\circ}$ from horizontal. With these geometric angles, each diagonal member meets with each column at beam column joint (Figs. 8, 9) in a panel. Buildings without braces are considered to have $0^{\circ}$ 
Fig. 6 Shear lag effect in 120 stories high building. Flange and web panels are shown

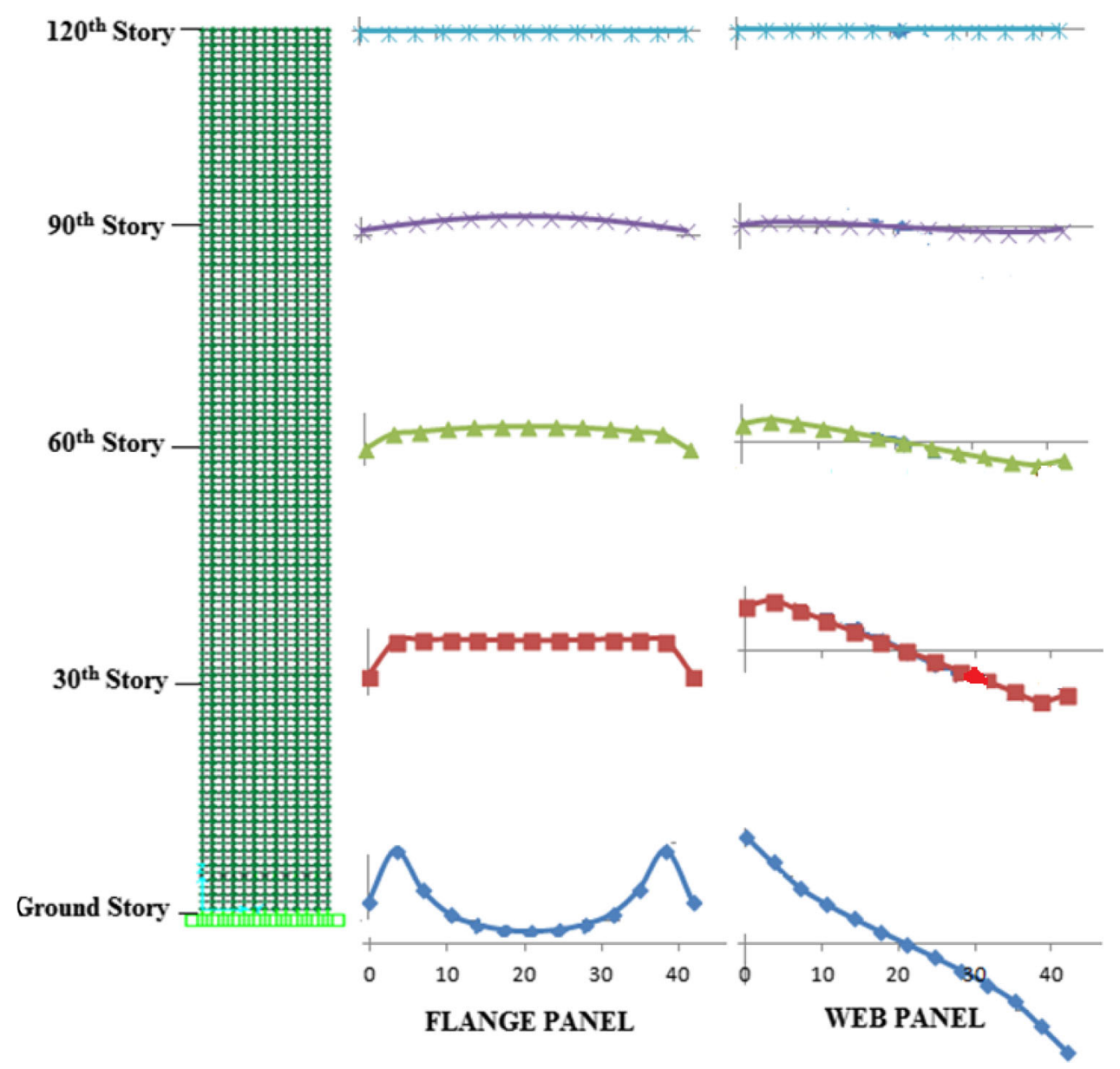

optimal angle should lie between $35^{\circ}$ and $90^{\circ}$. Now, objective of this study is to find the variation of shear lag as the height of the building changes. Also study the shear lag with the changing pattern of bracing systems and to correlate it with the overall stiffness of the building and hence to conclude about the overall performance of the buildings.

Fig. 7 Variation of shear lag ratio versus the story number

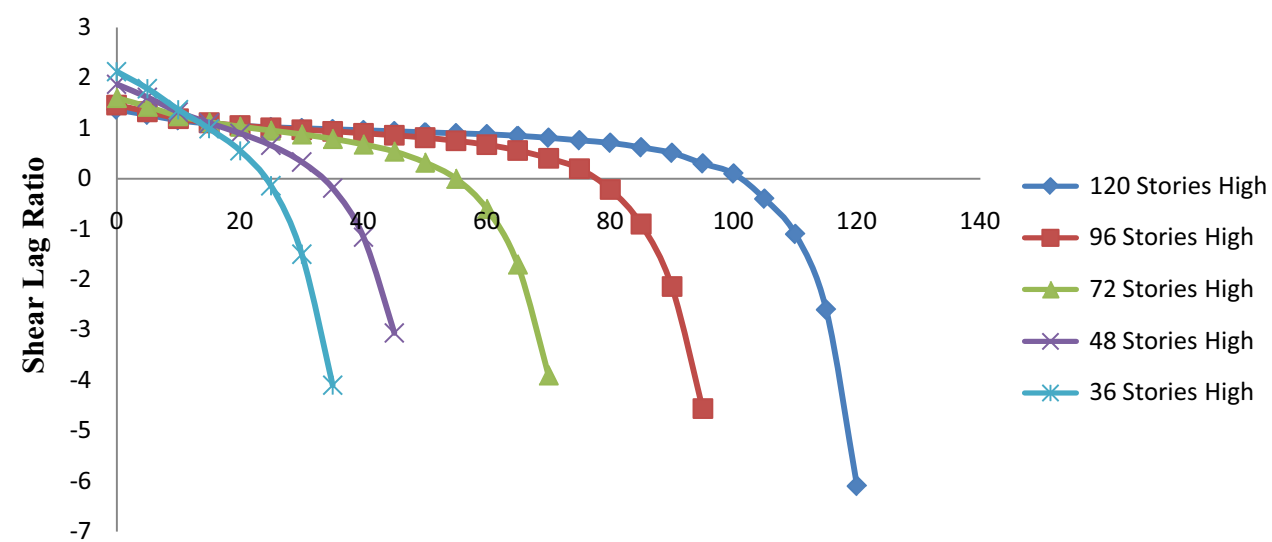

Building Height 


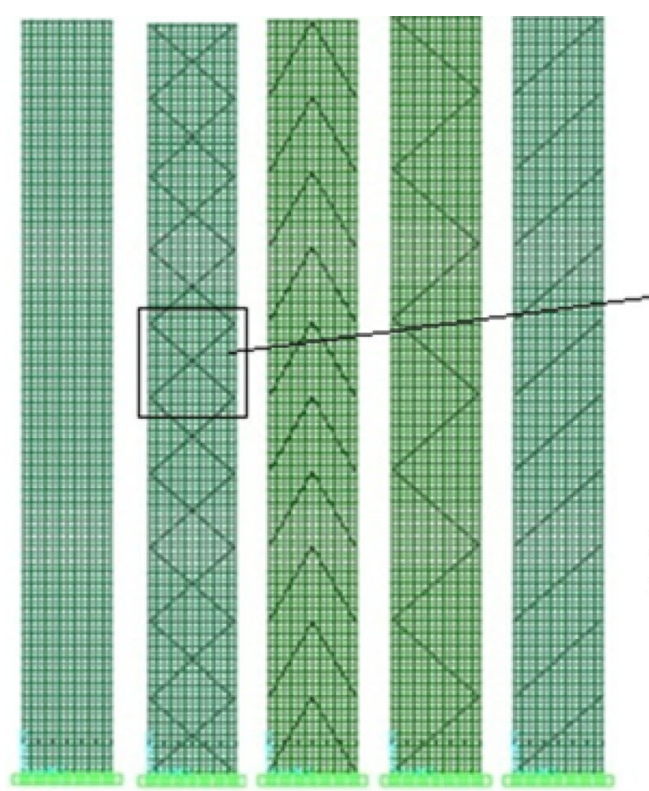

Model 0 Model 1 Model 2 Model 3 Model 4

Fig. 8 Bracing systems of different patterns considered in this study. Bracing angle is $45^{\circ}$ from horizontal. Only 120 stories high buildings are shown

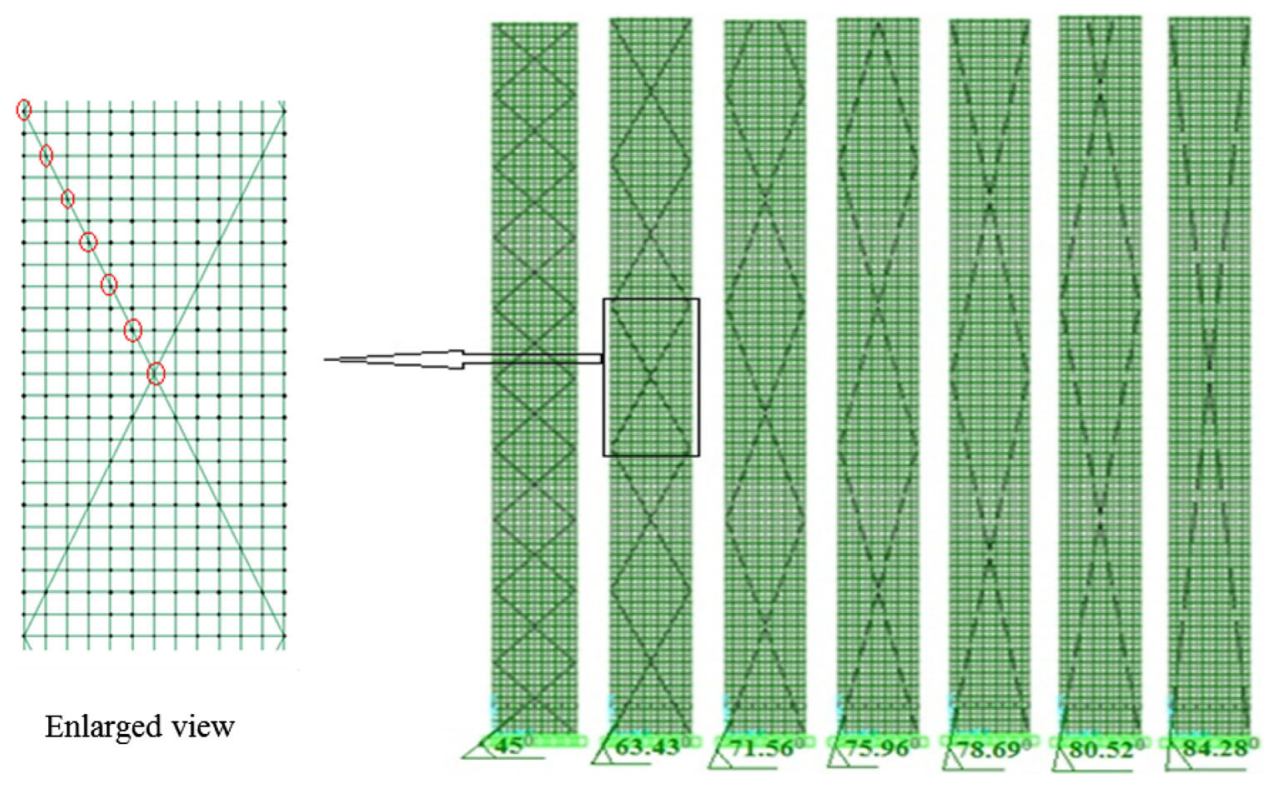

Fig. 9 Buildings of model 1, different alignments of bracings in 120 stories high buildings are shown

\section{Optimum design strategy}

Suppose $B$ and $L$ is the width and height of the building, respectively. With bracing angle $\theta$ from horizontal, total length of one bracing becomes (Fig. 10)

$=L / \sin (\theta)$.
If $A$ is the cross-sectional area of bracing element then total volume of steel used for one single brace $=A \times L / \sin (\theta)$.

Taking example of buildings of model 1 , there are two bracing members in a panel and there are four such panels 
in a building. So total volume of steel used in this type of model is

$=4 \times 2 \times A \times L / \sin (\theta)$.

As length of the building $(L)$ as well as member crosssectional area $(A)$ remains same for a particular height, this volume of steel depends on the bracing angle $\theta$ only.

Fig. 10 The length and width of the building with bracing of angle $\theta$ from horizontal are shown

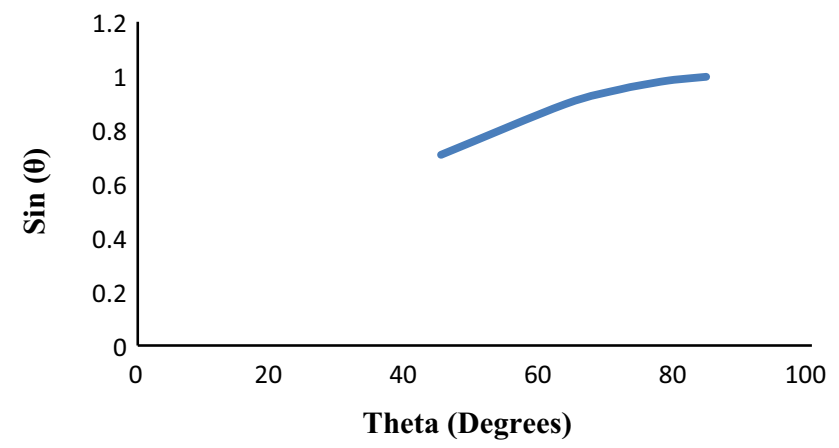

Fig. 11 Variation of $\sin (\theta)$ with varying $\theta$ from $45^{\circ}$ to $90^{\circ}$
As angle changes from $0^{\circ}$ to $90^{\circ}$, value of $\sin (\theta)$ increases as can be observed in Fig. 11. Hence volume of steel used decreases with increasing values of $\theta$.

So, material usage is minimum for bracing angle $84.28^{\circ}$ and maximum for $45^{\circ}$ but can be said as optimum for the angle for which lateral deflection of building is minimum.

\section{Results and discussion}

In a building, at the ground story columns, shear lag effect is most dominating and most influential because of large magnitude of axial stresses. For further analysis and comparison purpose shear lag ratio at ground story is considered for all heights and for all models.

\section{Results for buildings of model 1}

For this kind of bracing pattern, optimal angle for shear lag ratio lies between $45^{\circ}$ and $63.43^{\circ}$ for all heights of buildings. For 120,96 and 72 story high buildings, $63.43^{\circ}$ is the optimal angle and for 84 and 36 story high buildings, $45^{\circ}$ is the optimal angle.

Now considering the graphs of Figs. 12 and 13 in which shear lag ratio and top lateral deflection, respectively, are varying versus the bracing angle. Comparing these variations, it seems almost parallel variation among the two. It represents that by providing this geometric pattern of bracing system, building's stiffness varies the way shear lag varies in a building.

Looking close to the geometric pattern of this bracing, at any cross section of a panel there are two bracing members and each goes through the panel from one end to another. In this type of geometric pattern load transfer path is most continuous to the ground.
Fig. 12 Variation of shear lag with varying angle of bracing system for buildings of model 1

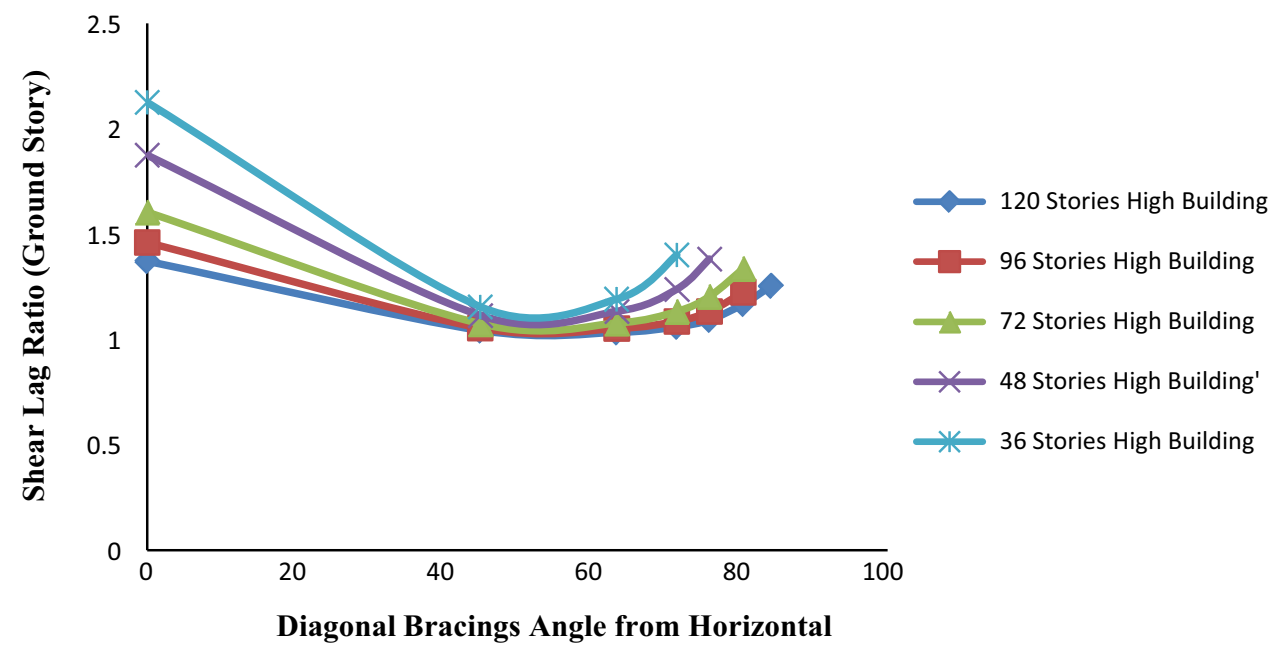



system for buildings of model 1
Fig. 13 Top lateral deflection versus varying angle of bracing
Fig. 14 Variation of shear lag ratio with varying angle of model 2 bracing system for buildings of
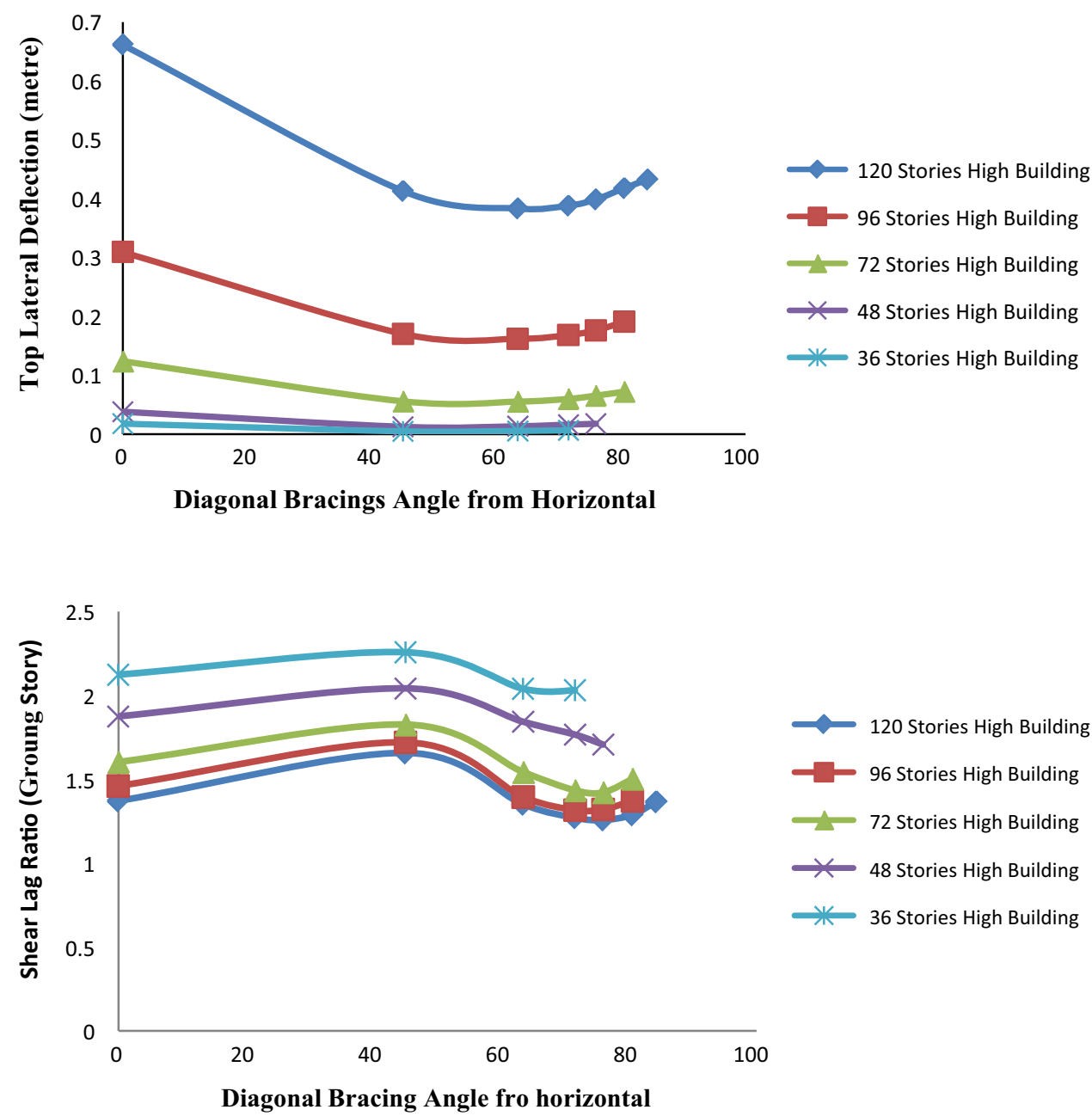

Fig. 15 Top lateral deflection versus varying angle of bracing system for buildings of model 2

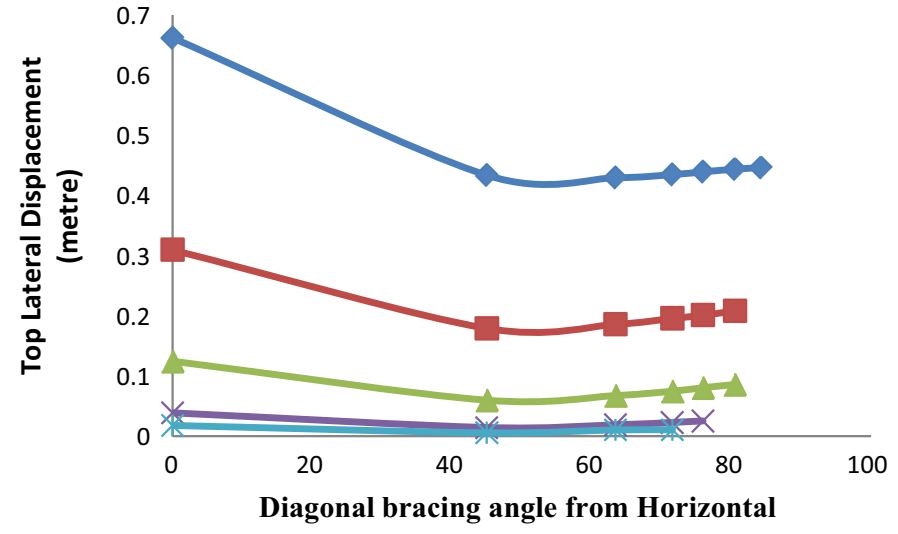

\section{Results for buildings of model 2}

In this type of bracing pattern, diagonal members do not continue through the panel instead it ends in the middle of it. This way load transfer path does not continue through to the ground.
At the joint where two of the bracing members are meeting, axial load distributes among the bracing members, thereby decreasing the axial force in the middle of the column. At the other end, in the corner columns this axial force increases. 
Fig. 16 Variation of shear lag with varying angle of bracing system for buildings of model 3

Fig. 17 Top lateral deflection versus varying angle of bracing system for buildings of model 3
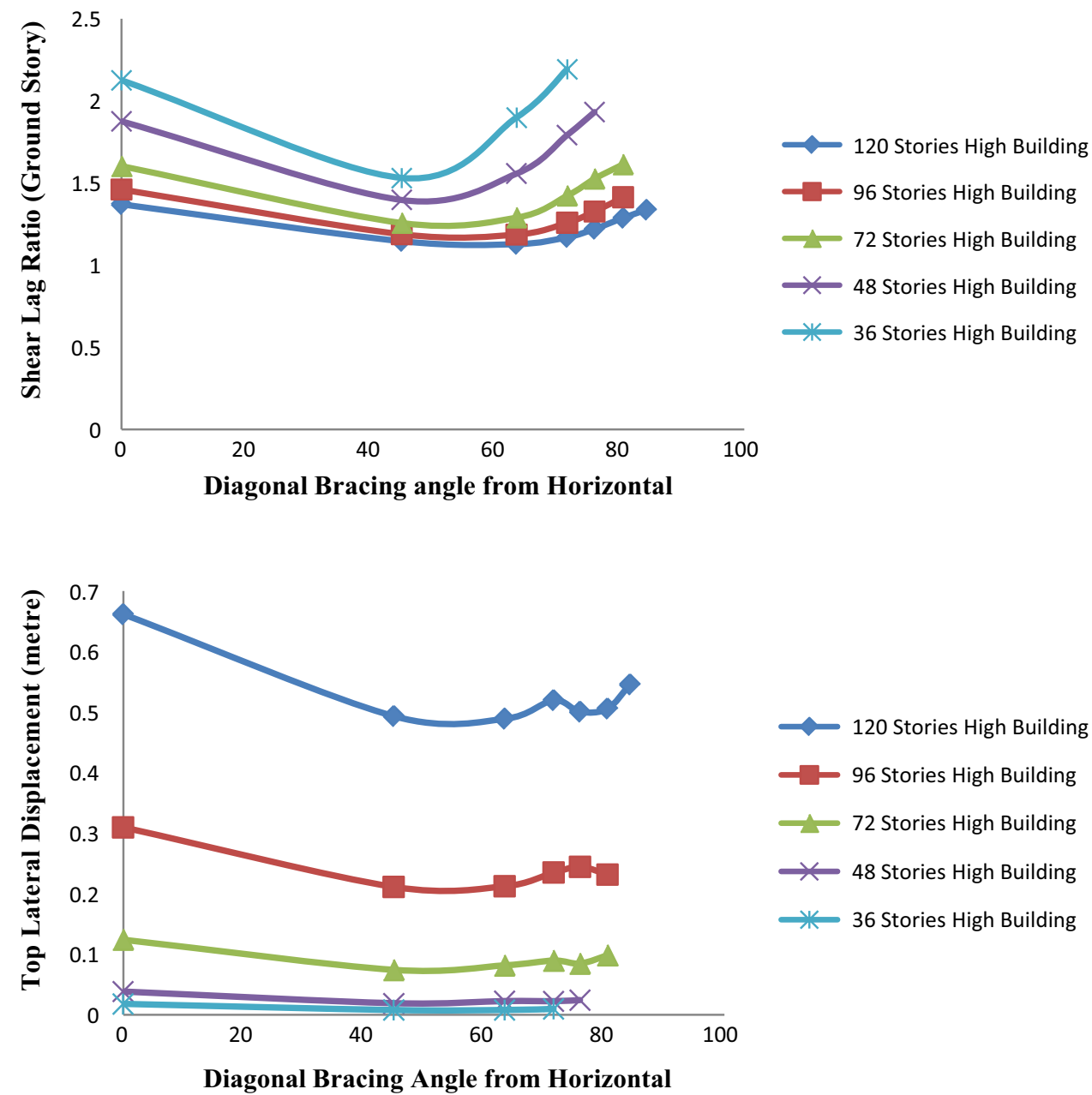

Fig. 18 Variation of shear lag with varying angle of bracing system for buildings of model 4

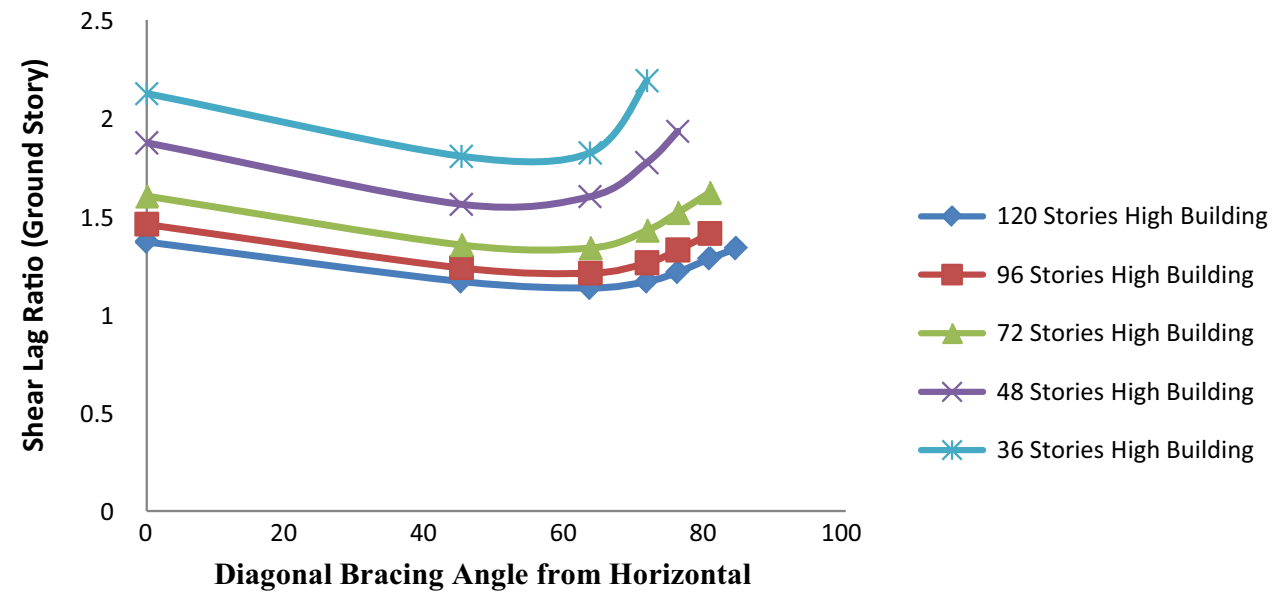

Shear lag ratio is nothing but the ratio of maximum to minimum axial stress in flange panel. This geometry affects more for shorter length or for small inclinations, whereas it decreases with increasing inclination. So shear lag ratio is suppose to be high for small inclinations of bracing angle and supposed to decrease as the angle of inclination increases. This variation can be observed in graphs of Fig. 14.

For 120 stories high building, $63.43^{\circ}$ is the optimal angle and for rest of the heights, $45^{\circ}$ is the optimum angle (Fig. 15). Although, for this kind of bracing pattern, optimum angle is again between $45^{\circ}$ and $63.43^{\circ}$, variation of 
Fig. 19 Top lateral deflection versus varying angle of bracing system for buildings of model 4

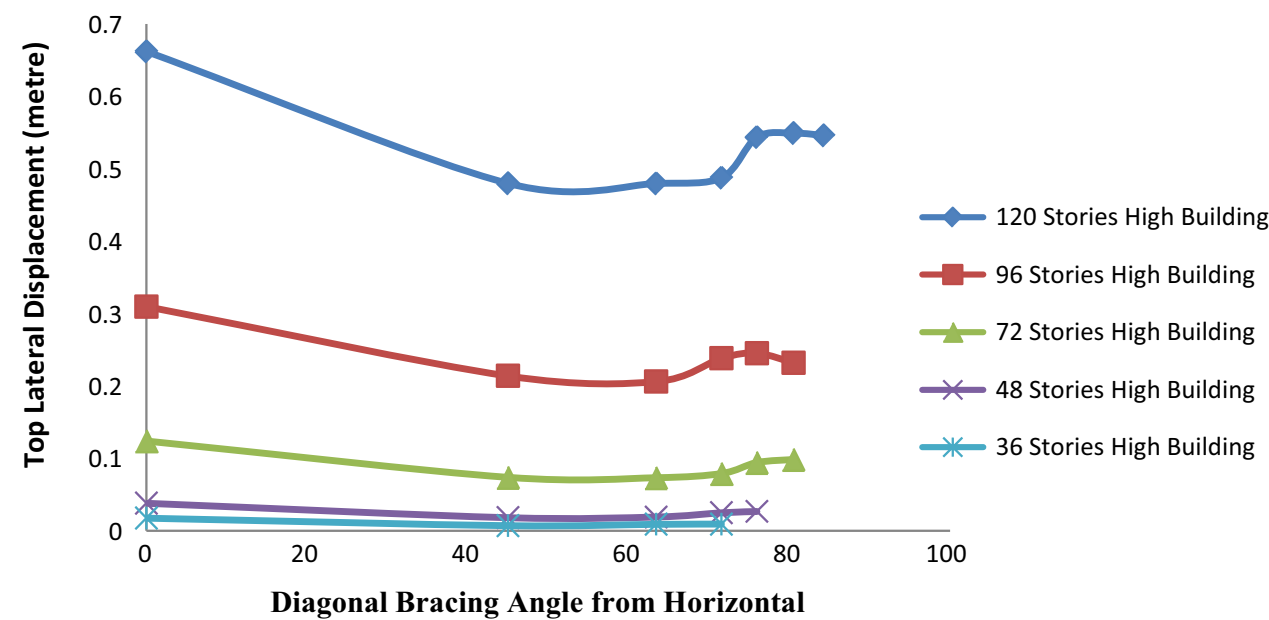

It is found that for all building models, bracing angle of $63.43^{\circ}$ shows the least lateral deflection for 120 stories high building and for 48 and 36 story high buildings, least top lateral deflection is coming for the bracing angle of $45^{\circ}$ for all heights. For the heights between 120 and 48, least lateral deflection is fluctuating among the values $63.43^{\circ}$ and $45^{\circ}$ for all models.

Again, building models 1 and 2 have two bracing elements in a cross section of any panel, whereas models 3 and 4 are having only one bracing element in a panel. Therefore, for a material-saving design perspective, it is not possible to compare all four models together but can be done separately.

Among all models, lateral deflection of 120 stories high building with bracing angle of $63.43^{\circ}$ is taken and compared (Fig. 20). It can be concluded with this comparison that bracing pattern of building model 1 is the best selection among models 1 and 2 and building model 4 is the best selection among models 3 and 4.

Among all building models, it is found that for buildings of model 1, shear lag varies the way building's stiffness is varying. Although providing other configurations of bracing in a building are not showing any negative effect,

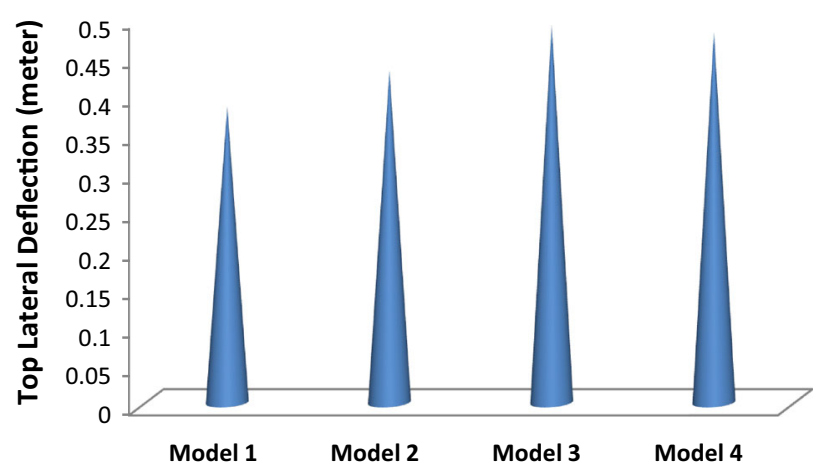

Fig. 20 Top lateral deflection of buildings of 120 stories high with bracing angle $63.43^{\circ}$ of all models 
bracing configuration of model 1 can be said as the best selection among all models.

Open Access This article is distributed under the terms of the Creative Commons Attribution 4.0 International License (http://crea tivecommons.org/licenses/by/4.0/), which permits unrestricted use, distribution, and reproduction in any medium, provided you give appropriate credit to the original author(s) and the source, provide a link to the Creative Commons license, and indicate if changes were made.

\section{References}

Ali MM, Moon KS (2007) Structural developments in tall buildings: current trends and future prospects. Archit Sci Rev 50(3):205-223

BIS (1987) IS 875 (Part 3) - 1987 Indian standard code of practice for design loads (other than earthquake) for buildings and structures. Bureau of Indian Standard, New Delhi

Leonard J (2007) Investigation of shear lag effect in high rise buildings with diagrid system. Massachusetts Institute of Technology, Cambridge
Mark S (2011) Tall building design inspired by nature. In: 36th conference on our world in concrete and structures, Singapore

Mendis P, Ngo T, Haritos N, Hira A, Samali B, Cheung J (2007) Wind loading on tall buildings. EJSE Spec Issue Load Struct 3:41-54

Moon KS (2008) Material-saving design strategies for tall building structures. In: CTBUH 8th world congress, Dubai

Moon KS (2009) Design and construction of steel diagrid structures. NSCC, School of Architecture, Yale University, New Haven, USA

Moon KS (2012) Optimal structural configurations for tall buildings. Hokkaido University, School of Architecture, Yale University, New Haven, USA

Moon KS, Connor JJ, Fernandez EJ (2007) Diagrid structural systems for tall buildings: characteristic and methodology for preliminary design. In: Lu X (ed) The structure design of tall and special buildings, vol 16, pp 205-230

Siavash K (2001) Optimal conceptual design of high-rise office buildings. University of Waterloo, Ontario

Thomas BV, Viktor S (2010) Adaptable high-rise buildings. In: 8th fib PhD symposium in Kongens Lyngby, Denmark 